\title{
Strategies to Improve the User Experience
}

\section{Buddy Pennington, Suzanne Chapman , Amy Fry , Amy Deschenes \& Courtney Greene McDonald}

To cite this article: Buddy Pennington , Suzanne Chapman , Amy Fry , Amy Deschenes \& Courtney Greene McDonald (2016): Strategies to Improve the User Experience, Serials Review, DOI: $10.1080 / 00987913.2016 .1140614$

To link to this article: http://dx.doi.org/10.1080/00987913.2016.1140614

Accepted author version posted online: 06 Feb 2016.

Submit your article to this journal $\widetilde{ }$

Џ Article views: 13

Q View related articles ¿

View Crossmark data 


\title{
ACCEPTED MANUSCRIPT
}

Strategies to Improve the User Experience

Buddy Pennington, Column Editor ${ }^{1, *}$, Suzanne Chapman, Contributor ${ }^{2}$, Amy Fry, Contributor ${ }^{3}$, Amy Deschenes, Contributor ${ }^{4}$, Courtney Greene McDonald, Contributor ${ }^{5}$

${ }^{1}$ Director of Collections and Access Management, Miller Nichols Library, University of Missouri -- Kansas City, 800 East $51^{\text {st }}$ Street, Kansas City, MO, 64110, USA; phone: 816-2351548; email: penningtonb@umkc.edu

${ }^{2}$ User Experience Librarian, University of Illinois at Urbana-Champaign, 1408 W. Gregory Dr., Urbana, IL 61801; phone: 217-333-2290; email: suzchap@illinois.edu

${ }^{3}$ Electronic Resources Coordinator, William T. Jerome Library, Bowling Green State University, Bowling Green, OH; phone: 419-372-2690; email: afry@bgsu.edu

${ }^{4}$ User Experience Specialist, Harvard Library, Cambridge, MA 02138, USA; phone: 617-4962619; email: amy_deschenes@harvard.edu

${ }^{5}$ Head, Discovery and Research Services, Indiana University Bloomington, Herman B Wells Library, 1320 E 10th Street, Bloomington, IN 47405; phone: 812-855-4217; email: crgreene@indiana.edu

*Corresponding Author Email : penningtonb@umkc.edu

Column: Electronic Resources Forum

\begin{abstract}
Libraries are increasingly embracing user experience (UX) and user-centered design principles to improve the satisfaction and success of library users. Electronic resources management can utilize such principles to better support users as they interact with the library's website and its
\end{abstract}




\section{ACCEPTED MANUSCRIPT}

electronic resources. In this column, four academic librarians discuss strategies libraries can employ to improve the user experience. These strategies include utilizing basic UX principles when designing sites and interfaces; analyzing quantitative data to inform the library on how such sites are being used; recruiting strategies for library user studies; and, finally, a call to move to a more unified user experience and to work more closely with vendors on improvements to help users succeed. 


\section{ACCEPTED MANUSCRIPT}

\section{Introduction}

In my previous column (Pennington, 2015), I introduced the field of user experience (UX) and user-centered design as one in which academic libraries could utilize to overcome the challenges of providing electronic resources to our users in a manner that better supports their work. For too long, we have relied upon a tool-based approach of linking to a myriad assortment of platforms and interfaces organized around how we, not our users, use them to manage our electronic resources. This approach, coupled with our librarian tendencies to supply users with as many options as possible, has resulted in complex library websites that our users are increasingly challenged and frustrated by.

To discuss the application of UX to library websites and electronic resources management, I have invited four librarians to share their views and experience. Suzanne Chapman, user experience librarian at the University of Illinois at Urbana-Champaign, begins by describing some basic UX principles that libraries can use when designing web pages that connect users to electronic resources. This is followed by Amy Fry, electronic resources coordinator at Bowling Green State University, who discusses reviewing usage data as a strategy to inform libraries of how users interact with the library and reveal further avenues of user research. A critical aspect of user experience is to understand user needs and behaviors. Amy Deschenes, user experience specialist at Harvard Library, provides some practical tips and tricks libraries can employ to recruit users for user studies. Finally, Courtney Greene McDonald, head, Discovery and Research Services at Indiana University Bloomington, presents a call to action in moving toward a more unified user experience and in sharing our understanding of users with library vendors so that they can improve their tools and interfaces to better support the work of library users. 


\section{ACCEPTED MANUSCRIPT}

Section 1. On the Shoulders of Design: Basic UX Principles Every Librarian Should Follow Suzanne Chapman

User Experience (UX) is a set of strategies for understanding users' needs and behaviors and then applying that understanding to designing useful, usable, and aesthetically pleasing systems and services. Although there is no substitute for doing user research, libraries often don't have the time or resources such research requires. This lack of resources, mixed with the desire to make data-driven decisions, can potentially result in a sort of user research paralysis -- that is, we don't want to make decisions without, data but we don't have time to collect the data, so we fall back to making design decisions by committee or making disconnected and uninformed decisions under deadline. Fortunately, we have access to an expansive body of knowledge generated by the fields of cognitive science, human-computer interaction, and user experience, which supports some basic, universal principles that can reliably inform design and content decisions.

As noted in an earlier article by Pennington (2015), "academic library websites are complicated." The more complex a website is, the greater the "cognitive load" (i.e., the amount of brain power it takes to accomplish a task). The greater the cognitive load, the more difficult it will be for the user to accomplish their task (Whitenton, 2013). The more complicated our websites are, the harder we have to work to make it easier. Although this may seem overwhelming, high-impact improvements can often be achieved through small changes. As Charles Eames famously said, "the details are not the details, they make the design." The following are just a few key concepts and design principles that will help you make more informed decisions.

1) Define a path with visual hierarchy. 


\section{ACCEPTED MANUSCRIPT}

People have an innate desire to make sense of visual clutter. The cognitive load this requires can be reduced by using basic design principles to provide a clear visual path to direct user attention where it needs to go.

Hierarchal organization is a powerful way to simplify the complex, especially when applied to design and content. Gestalt psychology theory proposes that the mind copes with visual chaos by constantly striving to make sense of things. More specifically, our minds tend to process the whole of an object before the parts (in fact, we process the whole as more than the sum of its parts), fill in gaps, seek to avoid uncertainty, and we are good at recognizing similarities and differences (Bradley, 2014). In cases where cognitive load is high, undesirable phenomena like "illusory correlation" can emerge wherein users overestimate connections between pieces simply because they expect a pattern to exist (Fiske \& Taylor, 2008).

Design principle: Chunking

Objects close to each other tend to be perceived as being more related than objects that are farther apart. Use the principle of chunking to make connections between like items clear and to make complex information easier to parse. For example, think about the phone number format convention -- it would be a lot harder to parse out or remember the numbers if they were presented as a continuous string of numbers: 8583466430 .

A listing for Serials Review in an online journal finder interface provides a good basis for applying this principle. As seen in example A (figure 1), it's very difficult to tell where one item ends and the next item starts because the spacing within items is the same as between items. A user is forced to ponder whether "Available from 1975" belongs with the link above it or below 


\section{ACCEPTED MANUSCRIPT}

it. But in example B, reducing space within items and adding more space between items chunks the information, making the relationships clearer.

Design principle: Highlighting and prominence

Additional focus can be achieved through the use of color, typeface, size, bolding, italicizing, or underlining. When used well and with moderation, highlighting can be used to draw attention to important elements, further setting them apart. Of special consideration are elements that aim to solicit action from the user. These are referred to as "call-to-action" items. In example C (figure 2), the journal title has been increased and bolded to separate it out as the main piece of information and the supplemental information below the link has been indented to further stress that it belongs to the link above it. In example $\mathrm{D}$, the link used to access the resource has been changed to a call-to-action button to help stress the action of going to this resource, and the supplemental information text has been decreased in size to show that it is secondary information.

Attention should also be paid to not highlighting elements in a way that entices action when no action is offered. In other words, don't make something look clickable when it isn't. This principle was discovered by Betz and Hall (2015) during usability testing of an institutional repository where use of decorative icons and text resulted in half of their participants misunderstanding these as paths to deposit items.

2) Keep it simple.

According to the Pareto Principle (also known as the 80/20 rule), $80 \%$ of a product's usage involves only $20 \%$ of its features (Lidwell \& Holden, 2003). This means that about $80 \%$ of what is presented to the users could be getting in their way and adding to their cognitive load. In the 


\section{ACCEPTED MANUSCRIPT}

context of a library website, this principle should inform site design in general, the way we embed features and tools in our catalogs and search interfaces, and also the way we approach creating the content that populates our websites. There are three attributes that contribute to cognitive load: the amount of thought required to make a decision, being unsure about the choices provided, and the number of choices (Julien, 2006). In order to reduce the load on users, we need to identify and deliver the most high-use content and features as clearly as possible. Design principle: Choice simplification Although example D (figure 3) provides a more explicit call-to-action, there is still information that must be processed before making a choice. In example E, by moving "Full Text" to the callto-action label, the user who is simply looking for access to full text will be able to make that decision just a little faster because the button label better matches their goal and the user who needs a certain vendor or year range will be able to parse that faster as well because there is less text to process and the vendor name pops out better.

Design principle: Choice reduction

Hick's law states that every additional choice option increases the time required to choose any option (Lidwell \& Holden, 2003). Although our instincts may be to offer an exhaustive list of options and prominent access to advanced features just in case a user needs it, we may be doing a disservice to the majority of our users who do not have preferences or advanced needs. We can reduce the burden of choice by either highlighting one or two options as "recommended" (example F, figure 4) or hiding redundant options (example G) so they aren't visible but are still accessible when needed.

Conclusion 


\section{ACCEPTED MANUSCRIPT}

Finally, it is worth briefly noting that there is a wide range of study into visual perception and usability. Some research suggests there is a direct correlation, called the "usability-aesthetic effect" wherein attractive designs are perceived as being more usable than unattractive designs (Lidwell \& Holden, 2003). Norman (n.d.) discusses this at length in numerous publications. "Good design," Norman avers, "means that beauty and usability are in balance. An object that is beautiful to the core is no better than one that is only pretty if they both lack usability" (2002). A library website's primary role is in helping users get their work done. The website is certainly a portal to useful resources, but, like the library itself, the website is much more than a simple container or gateway. A good library website mediates access through clear and thoughtful design. If we can't always take the time to manage every aspect of the design work perfectly, we can still do better, and doing better is achievable with basic principles.

Section 2. Listening to Data

\section{Amy Fry}

Anecdotal evidence about how students use my academic library at Bowling Green State University (BGSU) and their level of information literacy is sobering. This fall, I asked a class to do an activity after I introduced a number of library resources and how to use them; when I asked them what they used to complete the activity, one said she had just used Google, and she found a website from the Kennedy Center, and that was a reputable organization, so it should be fine. She hadn't even bothered to see how findings from library databases might compare. In another class, I talked about how Google can provide great sources, but it shouldn't be the only place you look. When I asked if the students had any questions, all their questions were about how they 


\section{ACCEPTED MANUSCRIPT}

were having trouble citing pdfs they had found as the result of Google searches. It hadn't occurred to them that perhaps those sources they'd found, whose format was unclear to them and which were missing valuable publication information, might not be good ones, nor that they were wasting time trying to figure out how to cite them rather than just using books and articles they could find through the library. In a recent research meeting, a student showed me a book chapter she had found on Google Books that she was going to use as a source for a paper. She hadn't realized that a number of pages were missing from the preview and hadn't thought to see if we had the book in the library -- which we did.

In light of this grim anecdotal evidence, it is fortunate that we also have data we can turn to. Circulation statistics, database and ejournal usage, website stats, and chat reference stats can all work together to paint a picture of how our constituents use library materials, one that can be more robust than what anecdotal evidence provides.

In fall 2015, we began a subscription to a service called Inspectlet, which records and saves videos of people using our website, including information on their browser, referrer, and whether or not they are using a mobile device. Watching these videos has been time consuming, but instructive. I watched about 300 , choosing both a random sample of the first thirty days of our subscription plus all the videos from one day in September. Ninety-seven percent were recorded between 9 p.m. and 8 a.m. or on the weekends and thus were unlikely to represent use from fulltime employees.

I learned that two-thirds of those uses were from on campus and $89 \%$ were from computers instead of mobile devices. Half of the few mobile users only wanted to view our hours. Over 


\section{ACCEPTED MANUSCRIPT}

$41 \%$ of users arrived at the library's website by linking through a top-level BGSU webpage and another $31 \%$ were referred by an Internet search. Two thirds of visits were research-related, with searching in the Summon or EBSCO search boxes on the home page being the most popular activity. Far fewer searched the catalog or linked to a database not in our EBSCO suite. Many people pasted searches they had copied from elsewhere, including book titles or article citations. Many keyword searches contained spelling errors.

Even such a small snapshot reveals a number of details that can inform how we structure our website to aid users. Obviously navigation from the university website to the library's home page is still important and provides the majority of users with their preferred pathway to access library resources online. We need to make sure that the owners of these pages are aware that these library links are used. Learning that relatively few of our users are using smartphones for research is somewhat a relief (since I know not all of our resources are accessible from small screens) but also shows a huge area of potential development for our library.

Because Summon is clearly our most-used tool, complete representation of our resources in Summon is essential, and we should continue to keep Summon coverage in mind when selecting and acquiring new resources. Indeed, users benefit from using Summon because it corrects spelling, strips out punctuation, and effectively boosts known-title matches to the top of search results. Neither EBSCO nor our catalog does this as effectively. Therefore, we should also encourage our librarians to provide training on using Summon at the reference desk and in the classroom to help our users have the best search experience they can on our website. 


\section{ACCEPTED MANUSCRIPT}

Users seem to know what EBSCO does and how to use it effectively. Our challenge is clearly to improve the visibility of databases we do not have through the EBSCO interface and train users how to find and link to those resources. This information can help us restructure how we provide access to them on our website and integrate them better into our webpages. For example, we are currently working on improving how individual databases appear in Summon search results in order to help users find them.

Inspectlet videos confirm that, while our dropdown menus on our home page are used, most users do not seem to find what they are looking for easily in them. These should be refined so only the most valuable links are listed, particularly those that highlight library services or resources that cannot be searched through our tabbed search boxes. And since few users scroll below the fold on our home page, valuable links below the fold should be moved up.

Website use is just one way to collect data on how users use collections. Last year I compiled data on the use of our circulating monographs acquired since 2008 by subject and method of selection. I learned that $74 \%$ of the monographs we'd purchased in $2008-2009$ and $64 \%$ of the monographs we'd purchased between 2008 and 2013 had been used by fall 2014. Examination of the use of ebook packages acquired during the same time indicated that only $12 \%$ of ebook titles had been used. This information informed our budgeting for 2015-16, in which we will maintain print spending while focusing ebook purchases on consortial and demand-driven titles in order to get the most return-on-investment for ebooks, which are in comparatively lower demand.

Our chat box appears in our EBSCO interface and on our ProQuest 360 Link (the link resolver) pages and is linked from Summon. As a result, our reference chat statistics also provide 


\section{ACCEPTED MANUSCRIPT}

illuminating data on how people use our resources. More and more users are contacting the library during their research experience, whether to communicate about problems logging in to full text, to ask what to do when no full text is available, or to seek advice on how to revise searches for better results. In the last year, I used our chat logs to develop troubleshooting training for librarians and staff who work at public services desks as well as student workers in circulation and reference.

We do not have to rely on unpromising anecdotal evidence to know how our users are using the library. But gathering the data, figuring out what it is telling us, communicating this information to colleagues, deciding how to respond, and implementing changes as a result is challenging. It takes time, skill, and teamwork. It can be tempting to short-circuit that process to rely on what we think we know or only do what our loudest users or most powerful constituents tell us they want, but developing solutions that really meet the needs of users requires us to put forth effort and openness in order to listen to the data.

\section{Section 3. Practical Tips for Recruiting Participants for Library User Studies} Amy Deschenes

User experience studies and electronic resources

Performing user experience (UX) research on how users interact with your library's website, discovery system, or other electronic resources can provide you with an abundance of useful information. You may choose to conduct an attitudinal study to find out what users think or what their level of satisfaction is through a survey or interview or a behavioral study, like a usability test, to observe how they perform certain tasks. The data you collect provides information you 


\section{ACCEPTED MANUSCRIPT}

can use to tweak the interface's customizations or change the resource's settings. In order to conduct a successful UX study you will need a clear focus, similar to a research question, and a group of users to actually participate in your study.

Although there may be a variety of user behavior and opinions about electronic resources that are "interesting," it is important to focus your testing on areas that are in your control. Using the administrator account in an electronic resource, you can typically change certain local settings such as the layout of the search pages, the library branding options, or the wording and look of the "Find Full-Text" button, but may not be able to alter vendor-managed options like the number of facets provided or the size of the article titles. When developing the questions you ask users or the tasks you ask them to perform, be sure to focus in on what you can control from the administrator account rather than areas that can only be changed by the resource's vendor. If you find a problem with the interface, you can certainly pass it along to the vendor, but they likely (or should) have teams already performing internal usability or quality assurance testing. Your focus should be on what you can control for your local users.

Finding participants is an often overlooked, but crucial step in carrying out a UX research project. Without proper planning, it can be challenging and time-consuming to recruit and schedule research participants. Rather than letting your study turn into a logistical nightmare, create a plan for how to handle recruitment as you develop your study methodology. Recruiting the appropriate participants and preparing for unfortunate inevitabilities (like no-shows) will make data collection much simpler.

To successfully determine which users to recruit you need to: 


\section{ACCEPTED MANUSCRIPT}

- Make sure your study has a clear goal. Why are you doing it? What do you want to learn? Are you looking for clear evidence that supports comments you've heard anecdotally such as "I can never find the full-text button" or "How do I search by author"? Do you want to know where people are encountering confusion with the interface's labels, buttons, or layout? Are you interested in how new or advanced users interact with the resource? Considering these questions as you develop your study will make it easier to figure out whom you should recruit to participate in the study.

- Consider your stakeholders. Is it important to ensure certain populations are included? Will you need to collect any information about your participants to demonstrate the test wasn't unfairly biased or excluded certain groups that should have been represented?

- Whenever possible try to include one or two users in your study pool who have vision, auditory, motor, or cognitive disabilities or who utilize assistive technology. These might be users with whom librarians on your staff already have a connection.

The group from which you recruit may be as broad as "any library user" or may be as specific as "adult education students over the age of 40." The only way you'll know whom to recruit is if your study has a clearly articulated goal.

Recruiting

There are two basic ways to recruit for a study:

1. In-advance recruitment is when you ask for volunteers to participate in advance of the study and have participants sign up for a certain time.

2. In-person recruitment is when you ask for volunteers to immediately participate in-person in a common area, like a lobby or cafe, as you encounter them. 


\section{ACCEPTED MANUSCRIPT}

In-advance recruitment

Recruiting users in advance of the study via an email message, social media announcement, or signage can make it easy to target certain populations. However, scheduling users can be timeconsuming and you will certainly have to manage no-shows and last-minute rescheduling requests. When using this approach, make sure you always over-recruit. If your study plan calls for 5-7 participants, recruit at least 10 participants.

If you're asking potential participants to sign-up for a study via email, make sure your email has a catchy subject line and is easy to read. If you're testing a specific resource like JSTOR or Academic Search Complete, you don't need to say that in the email, instead describe the study in general so users aren't turned off by unfamiliar terms. Be brief and only include the critical pieces of information. These include:

- A brief description of the test, including why they're being asked to participate.

-When the test will be conducted and how much time it will take.

- How they can sign up.

The layout is equally important to the content. People receive numerous emails, so make sure yours is eye-catching and contains easy-to-scan headings. No one wants to read an email with large blocks of text. Use large headings focused on the participant to separate sections. Here's an example of a recruiting email for a usability study:

Email Subject Line: The Library Needs Your Help

Dear Students,

The Library requests your participation in a study of part of our website. We're looking for students who have 30 minutes to use the site and provide us with feedback. Your 


\section{ACCEPTED MANUSCRIPT}

feedback is very important to us and will help us improve your experience. You'll receive a gift of [NAME OF INCENTIVE] for your participation.

What will I be doing for the study?

You will be asked to do several simple tasks using library websites. During the test we will record your screen movements and voice. You will be also asked questions about your experience and perceptions of the sites.

When \& Where?

The study will be held on the following dates in [LOCATION] and will take approximately 30 minutes.

- Date1

- Date2

- Date 3

How can I participate?

Please send an email to [EMAILADDRESS] with your contact information, graduation year, and preferred dates and 30-minute time slot.

Consider and plan for how to keep track of the sign-ups for participants, the schedules of any staff members involved with testing, and any rooms you need to book. Make sure you have staff available to conduct the study before sending out a recruitment email to potential participants. If you want to simplify the sign-up process, you could utilize an online tool, like the freely available slotted (https://www.slotted.co/), to manage participant sign-ups. The website enables you to create a public sign-up sheet that you can link to in any promotional materials. It will 


\section{ACCEPTED MANUSCRIPT}

automatically generate a reminder email to each participant in advance of the study date and time.

In-person recruitment

An alternative option is to recruit study participants in person. Although this poses fewer logistical challenges since there is no advanced scheduling involved, you also don't have much choice in who participates. You're limited to the people who happen to be walking by your inperson recruitment location. You can certainly target first-years or senior citizens specifically using clear signage, but you'll still only be recruiting the people who are actually coming into the space where you're recruiting. If you're okay with that limitation, in-person recruiting can be surprisingly easy.

Do you have a cafe in your library? A spot near the entrance where you can set up a table? Conducting tests using in-person recruitment works best when you have at least two staff members available for recruitment and test moderation. One person is the recruiter; he or she explains the study to passers-by and has them sign any consent forms. The other person moderates the study, either in the same location as the recruiter or in a nearby quiet room if necessary. Effective signage is crucial to successful in-person recruitment. Make sure your signage is sizable and easy to read. Consider adding an eye-catching graphic like a photo of whatever incentive you're offering to participants.

Other avenues

If you can't find participants, someone might suggest having student workers or employees act as your participants. However, in most types of user experience research, internal groups are not the best candidates for study participants. They are predisposed to using, and having opinions 


\section{ACCEPTED MANUSCRIPT}

about, the library since they work there. However, student workers are great candidates for pilot testing your tasks before launching your study. Additionally, student workers or employees probably have friends they'd be willing to ask about participating or may be part of student organizations that could help you test. Asking them to help with recruitment is a great way to simplify the process.

Incentives

Choosing the right incentives can make or break your study. Some people will do just about anything for a free king-size candy bar or coffee. Others might be motivated by the opportunity to secure first dibs on your library's New York Times bestsellers. Selecting the right incentives depends on how well you know your population. Do you always run out of headphones you lend at the circulation desk? Is the vending machine constantly running out of Clif bars? These might make excellent incentives in your next studies. If you're not sure what would motivate your library users, ask them by conducting a brief survey at the circulation desk or via email asking what type of "prize" they'd like to see in a future library promotion. Some ideas include coffee shop gift cards, technology charging cords, water bottles, or notebooks.

If you're running an in-person recruitment study, free food or candy bars are an especially effective incentive. You may even find that people are drawn to your set up because of your basket of candy, but don't actually take one after completing the study. Consider the time of day and your location as well. If you're setting up in the morning, have breakfast foods and coffee. If you're located next to the campus gym, offer nutrition bars and bottles of water.

Future UX research 


\section{ACCEPTED MANUSCRIPT}

Once you are running tests, don't let the opportunity pass by to understand the motivations of your participants. After the official research part of the session is over, ask them what they think would be popular among their peers for future giveaways or if there's a certain time of day for running studies that works best.

In addition to inquiring about incentives and timing, ask your participants if they'd be interested in helping out with future studies run by the library. Create a participant pool with past participants' names, email addresses, and any other relevant demographic information. This will make future recruiting for user experience research even easier, since you'll be working from a pool of willing study candidates.

User experience research is a valuable activity to improve the usability of your library's electronic resources. Once you have run one or two studies, consider creating an email or signage template that can be reused for future research recruiting. Like anything, recruiting participants gets easier the more you do it, and you will learn what motivates your users to participate. By articulating a clear recruitment strategy in your study plan you can simplify the process of finding participants for your research and put more focus on the data collection and analysis.

Section 4. Out of Many, One: Thoughts on Moving Toward a Unified User Experience

Courtney Greene McDonald

As Suzanne Chapman noted earlier in this column, Pennington (2015) began the previous installment of this series by stating "academic library websites are complicated... We know this because our users have told us" (p. 194). At Indiana University Bloomington, users reinforced 


\section{ACCEPTED MANUSCRIPT}

this notion. Shortly after starting my present position as head of Discovery and Research Services in 2010, I realized that as users told us about their problems with the website -- and believe me, there were problems -- part of the time they were actually talking about problems with our library catalog, IUCAT.

When I spoke with students about library systems, they were puzzled, understated, and endearingly polite. Did we realize that our catalog was really hard to use -- that it wouldn't even let them use the back button on their browser? Were we aware that searching library databases was, perhaps, not like Google and other tools that they and their contemporaries were accustomed to using? They were somewhat surprised to learn that we did and we were, and they were pleased that we agreed that improvements were needed. Since 2011, we have transitioned our primary public catalog interface to an open source discovery layer application (Blacklight, http://projectblacklight.org), launched a web-scale discovery tool EBSCO Discovery Service, locally branded as OneSearch@IU), and most recently, completed a massive website redesign project that migrated thousands of pages from a locally developed content management system (CMS) to Drupal. Drupal is a widely adopted open source product (https://www.drupal.org/).

Like many of academic libraries, we rely on numerous vendor-provided and open source services in addition to our integrated library system (ILS), our web-scale discovery interface, and our web CMS. We also rely on Serials Solutions' Electronic Resource Management system and link resolver to help us manage our nearly 1,000 databases; two SpringShare products (LibGuides and LibCal); a locally administered WordPress multiuser platform for library blogs; and LibraryH3lp, through which we offer IM reference services. These are only the products that I 


\section{ACCEPTED MANUSCRIPT}

and my department directly or collaboratively manage or with which we assist on a regular basis; there are many others.

What does this mean about how libraries do business? Hanson (2015), on a website, recently described our new reality:

Libraries are software. Our collections and services are delivered primarily via software. Most of our users' experience of the library occurs online and through software regardless of whether the user is physically present in the library. The choices we make in the development, selection, and implementation of this software are not incidental to our delivery of content and services. Rather, they define the limits of our content and services. We can only be as good as our software.

Sobering thought, but difficult to refute upon consideration of the thought, time, personnel, and budget we give to selecting, implementing, enhancing, and transitioning between the software interfaces that enable us to offer mediated and unmediated services and access to our physical and electronic materials.

Library professionals are accustomed to navigating within this patchwork environment, so it can be difficult to step back and realize that our users aren't and don't want to be. This seems to leave us in something of a dilemma since we've just established that software plays such a crucial part in our ability to interact with and serve our communities. In a 2013 blog post, Jonathan Rochkind summed it up nicely: 


\section{ACCEPTED MANUSCRIPT}

We libraries as customers would prefer to be able to 'de-couple' content and presentation. We want to be able to decide what content and services to purchase based on our users' needs and our budgets; and separately to decide what software to use for UX and presentation -- whether proprietary or open source -- based on the features and quality of the software, and our budgets. To make matters more complicated, we want to try and take our content and services -- purchased from a variety of different vendors -- and present them to our users as if it were one single 'app,' one single environment, as if the library were one single business.

From my own recent experiences, I've learned that this isn't easy (to put it mildly). To move from a landscape of systems that were, to varying degrees, no longer meeting the needs and expectations of our users to a forward-looking environment where we could begin to implement best practices in user experience (UX) and discovery required a commitment to "an overall effort to unify the Library Web presence and present the Libraries' collections, services, and resources in a way that enables a more holistic approach to supporting teaching, learning, and research in the Indiana University community." (Greene, 2012, p. 500)

The professional conversation now differentiates between discovery and discoverability, similar terms with a different focus; as defined in a recent SAGE white paper, discovery is "the process and infrastructure required for a user to find an appropriate item" and discoverability is "the description or measure of an item's level of successful integration into appropriate infrastructure maximizing its likelihood of being found by appropriate users" (Somerville \& Conrad, 2014, p. 3). As collectors, managers and preservers of collections, our focus has naturally gravitated 


\section{ACCEPTED MANUSCRIPT}

toward the item(s), but we have also grappled with the question of the quality and character of the user's experience with those items and systems. ${ }^{1}$

Steven Bell, who has written extensively on UX and related topics, defines UX quite broadly, often using the term "totality." He contrasts this with the concept of usability, which he gives a tactical focus (how easy is it to do a specific task): "The user experience, from my perspective, is about much more than usability. It's about designing an intentional, well-thought out experience that ensures the community member has a consistently great library experience at every touchpoint" (Bell, 2012). In a recent article in portal: Libraries \& the Academy, he comes back to the idea of a holistic, seamless deliverable when considering the question of "crafting systemic library experiences designed to deliver totality" and there, links it with design thinking: "To excel in a future characterized by greater uncertainty and rapidly shifting user needs, academic librarians must be skilled at identifying problems and then creating elegant solutions. That is the essence of design work" (Bell, 2014, p. 376).

Let's be honest: librarians may have 99 application, software, and platform problems, but identifying problems with those systems isn't one (usually). I think Steven Bell is implicitly asking us to consider whose problems we are identifying. We must remember always to question ourselves and our definitions of what makes a more usable system in order to hope to be trustworthy arbiters of what constitutes to a great user experience. This extends to how we identify and define problems, too. Stephen Abram quite rightly pointed out in 2013 that user and

\footnotetext{
${ }^{1}$ I encourage you to read Robert Taylor's masterful article on question-negotiation, still so very relevant nearly 50 years after its publication: "The inquirer is only concerned with getting an answer, not with system niceties. Nor is he interested in learning and maintaining currency with a system in which only a very minor part has relevancy to him" (1968, p.188).
} 


\section{ACCEPTED MANUSCRIPT}

librarian experiences in a system can diverge quite significantly: "Librarians don't necessarily test for things that align with end-user behaviors. ... their evaluations are, basically, driven by a different mindset about how search should work" (Abram, 2013, sec. Downside of Statistical Models).

This is slowly changing. Libraries are exploring tools and processes that introduce usability practices and standards into their own processes. For example, Purdue University experimented with integrating heuristic evaluation into their database review process; heuristic evaluation is a no-cost usability technique in which a small number of expert evaluators review and assess a site based on a set of ten agreed-upon usability principles (Nielsen, 1995). Barnes (2013) noted, "introducing more user experience parameters into the process allows librarians to record usability errors to be communicated back to database vendors or to be considered for database renewal and selection in the future at the Libraries" (p. 240). Others are contributing improvements to tools and interfaces, either as part of an open source software community, or directly to vendors themselves. Matthew Reidsma, who for some time has been "modifying vendor tools in ways that pleasantly surprise even the vendors," recently offered a course to enable others to do so as well. This abstract speaks to some of the concerns raised earlier: "Do you struggle to make a collection of difficult vendor tools feel like a cohesive suite of services?

Do you find yourself pleading with vendors to address usability issues?" (Reidsma and Infopeople, 2015)

I support and applaud the growing interest of the profession in working toward better usability, and I would love to see user testing become so common as to be unremarkable across the library 


\section{ACCEPTED MANUSCRIPT}

community. That said, I have a confession to make. You may be wondering about the period during which we were planning and implementing those major system changes. Had we done user testing, and what did it show? In some cases, the answer was no, we hadn't done user testing. Why? Because in those cases we already knew beyond the shadow of a doubt that the specific product in question (whether vended or locally developed) was so badly out of sync with any reasonable user expectations that we didn't need a test to tell us it was "broken." We needed a product that was able to be refined before it was worth our time, and the participants' time, to test.

Why, you might ask, am I allowed to take my own word for it that those systems were broken, when I was just moments ago emphasizing the importance of not doing that very thing? Because I wasn't actually just taking my own word for it. It was abundantly clear from fielding hundreds of reference queries, reading numerous user studies conducted at other institutions, and even from simple observation that we were "competing with [users'] own mental models of how search works and with their own systems of consuming and sharing information" (Daigle, 2013, p.326).

This brings me back to the questions posed in Buddy Pennington's previous column. "Are the decisions we make in how we present electronic resources to [users] grounded in their expectations and behaviors or in the systems we use to manage them? Do we even have a good understanding of how they interact with these electronic resources in the course of their research and academic activities" (Pennington, 2015, p.197)? 


\section{ACCEPTED MANUSCRIPT}

I might also add that the "we" in those questions must encompass our broader library community

-- not just libraries themselves, but our vendors as well. Abram noted, "Many vendors do research the user experience but keep it internally so they have a competitive advantage. They don't inform the community of their results, restricting learning, comment and debate" (2013, sec. Dynamic Tension). There is evidence that this too is changing. For example, EBSCO maintains a user research team, members of which regularly present findings at conferences, and Gale has partnered with UserTesting.com to enable customers to collect testing data on local interfaces and services (EBSCO Information Services, 2015; Howard-Hall, 2014).

It is incumbent upon us to engage with vendors, productively and positively, about issues related to usability. In order to do so we must first make usability a priority in our own thinking, and then it follows that we must make it a priority in our conversations with vendors as a routine part of purchasing and renewal cycles. But if this effort is to be successful, we must also be able to clearly articulate a collective, shared, agreed-upon definition of what constitutes good usability for library systems and products. Further, this definition must remain within the bounds of what is considered good usability for all web-based interfaces. We know standards are essential for good metadata; for usability, we must also commit to establishing standards where they do not already exist and abiding by them where they do: “... for us to have the impact we seek in the lives of our users, we must encode our services and our values in the software we provide" (Hanson, 2015). In a forthcoming issue of Weave: The Journal of Library User Experience, reviews editor Pete Coco plans to "feature a crowd-sourced tool that collection development librarians can use when evaluating vendor resources and which, we'd hope, catches on with vendors as a rubric for what libraries might need for UX" (Pete Coco, personal communication, 


\section{ACCEPTED MANUSCRIPT}

September 17, 2015). This is just the sort of thing we need to be undertaking as a community committed to user-centered design.

Beyond usable

Usability is an important aspect of user experience, but by itself, it's not enough. We know that we must seek to measure effectiveness of the systems and software we rely upon, but how can we reach ahead to know how not only to improve existing systems, but also to build new and better ones for the future? One road to an answer could lie with service design.

Service design in libraries can be defined as "looking at the entire service ecology of a library and the community it serves ... a holistic, co-creative method, [it] puts the user in the center of the service delivery model and focuses on the users' entire experience, rather than bits and pieces” (Marquez \& Downey, 2015, sec. Service Design, a Definition). Marquez and Downey outline, conceptually and practically, the steps needed to implement a service design methodology, which encompasses a number of phases and relies on a variety of data collection techniques. They also note this can have a positive impact on the library budget: "The service design methodology can assist in the creation and refining of services that are based on actual demand rather than creating services around national trends ... managers can be more informed when making budgetary and resource allocation decisions" (2015, sec. Conclusion). Daigle (2013) commented on the implications of the data-driven orientation of service design:

To develop services that are truly user-centered and, by extension, more compelling, useful and valuable we need to validate our assumptions about how users discover information, how they manage what they do find, and how they use it by allowing them 


\section{ACCEPTED MANUSCRIPT}

to show and tell us. We have to be prepared to act on what we learn and then validate whether or not those actions resulted in something better than it was before. (p. 331)

This combination of reflection and action seems to me to create the environment in which we will begin to build the elegant solutions that Steven Bell envisioned as key to the future of libraries.

But as I mentioned before, we must not undertake this in a vacuum, "Libraries, publishers, and vendors must partner to develop and pursue research studies on the role of digital content on a much greater scale" (Abram, 2013). Electronic resources librarians are perfectly situated to open a dialog with vendors that will enable staff across libraries to pursue opportunities of this kind. 


\section{ACCEPTED MANUSCRIPT}

\section{References}

Barnes, I.R. (2013). Incorporating usability into the database review process: New lessons and possibilities. Proceedings of the Charleston Library Conference. http://dx.doi.org/10.5703/1288284315267

Bell, S. J. (2012, May 29). Usability and user experience -- There is a difference. Designing Better Libraries. Retrieved from http://dbl.lishost.org/blog/2012/05/29/usability-and-userexperience-there-is-a-difference/

Bell, S. J. (2014). Staying true to the core: Designing the future academic library experience. Portal: Libraries and the Academy, 14(3), 369--82. doi:10.1353/pla.2014.0021.

Betz, S., \& Hall, R. (2015). Self-archiving with ease in an institutional repository: Microinteractions and the user experience. Information Technology and Libraries, 34(3), 4358.

Bradley, S. (2014, March 28). Design principles: Visual perception and the principles of Gestalt. Smashing Magazine. Retrieved from http://www.smashingmagazine.com/2014/03/designprinciples-visual-perception-and-the-principles-of-gestalt/

Daigle, B. (2013). Getting to know you: Discovering user behaviors and their implications for service design. Public Services Quarterly, 9(4), 326--32.

doi:10.1080/15228959.2013.842416.

EBSCO Information Services. (2015). User research. Retrieved from https://www.ebsco.com/why-ebsco/user-research

Fiske, S., \& Taylor, S. (2008). Social cognition: From brains to culture. Boston: McGraw-Hill Higher Education. 


\section{ACCEPTED MANUSCRIPT}

Greene, C. (2012). The long \& winding road: Implementing discovery at Indiana University Bloomington Libraries. In Planning and Implementing Resource Discovery Tools in Academic Libraries, edited by Diane Dallis and Mary Pagliero Popp. Hershey, PA: IGI Global.

Hanson, C. (2015, September). Opinion: Libraries are software. Retrieved from http://codyhanson.com/writing/software.html

Howard-Hall, T. (2014, December 10). Gale customer care could be your key to success in boosting usage. The Gale Blog [Web log comment]. Retrieved from http://blog.gale.com/gale-customer-care-could-be-your-key-to-success-in-boosting-usage/

Rochkind, J. (2013, November 21). Library vendor wars. Bibliographic Wilderness [Web log comment]. Retrieved from https://bibwild.wordpress.com/2013/11/21/library-vendor-wars/

Julien, J. (2012, March 6). Cognition \& the intrinsic user experience. UX Magazine. Retrieved from http://uxmag.com/articles/cognition-the-intrinsic-user-experience

Lidwell, W., \& Holden, K. (2003). Universal principles of design. Gloucester, Mass.: Rockport.

Marquez, J., \& Downey, A. (2015). Service design: An introduction to a holistic assessment methodology of library services. Weave: Journal of Library User Experience, 1(2). doi:http://dx.doi.org/10.3998/weave.12535642.0001.201

Nielsen, J. (1995, January 1). How to conduct a heuristic evaluation. Nielsen Norman Group. Retrieved from http://www.nngroup.com/articles/how-to-conduct-a-heuristic-evaluation/ Norman, D.A. (2002). Emotion \& design: Attractive things work better. Interactions Magazine, ix (4), 36-42. Retrieved from http://www.jnd.org/dn.mss/emotion_design_at.html 


\section{ACCEPTED MANUSCRIPT}

Pennington, B. (2015). ERM UX: Electronic resources management and the user experience.

Serials Review, 41(3), 194--98. doi:10.1080/00987913.2015.1069527

Reidsma, M., \& Infopeople. (2015). Customizing vendor interfaces for better user experience.

Infopeople. Retrieved from

https://infopeople.org/civicrm/event/info\%3Fid\%3D498\%26amp\%3Breset\%3D1

Somerville, M. M., \& Conrad, L.Y. (2014)."Collaborative improvements in the discoverability of scholarly content: Accomplishments, aspirations, and opportunities. A SAGE white paper. SAGE Publications Ltd. Retrieved from

http://studysites.sagepub.com/repository/binaries/pdf/improvementsindiscoverability.pdf

Taylor, R.S. (1968, May). Question-negotiation and information seeking in libraries. College \& Research Libraries, 29, 178--94.

Whitenton, K. (2013, December 22). Minimize cognitive load to maximize usability. Nielsen Norman Group. Retrieved from http://www.nngroup.com/articles/minimize-cognitive-load/ 


\section{ACCEPTED MANUSCRIPT}

\section{Example A}

Serials Review
Full text available via Elsevier ScienceDirect Journals
Available from 1975
Full text available via EBSCOhost Academic Search Complete
Available from 1990
Most recent 1 year 6 months not available
Full text available via Taylor \& Francis Current Content Access
Available from 1997
Most recent 1 year 6 months not available

\section{Example B}

Serials Review
Full text available via Elsevier ScienceDirect Journals
Available from 1975
Full text available via EBSCOhost Academic Search Complete
Available from 1990
Most recent 1 year 6 months not available
Full text available via Taylor \& Francis Current Content Access
Available from 1997
Most recent 1 year 6 months not available

Figure 1. Chunking. 


\section{ACCEPTED MANUSCRIPT}

\section{Example $\mathrm{C}$}

\section{Serials Review}

Full text available via Elsevier ScienceDirect Journals Available from 1975

Full text available via EBSCOhost Academic Search Complete Available from 1990

Most recent 1 year 6 months not available

Full text available via Taylor \& Francis Current Content Access Available from 1997

Most recent 1 year 6 months not available

\section{Example D}

\section{Serials Review}

Go Full text available via Elsevier ScienceDirect Journals Available from 1975

Go Full text available via EBSCOhost Academic Search Complete Available from 1990

Most recent 1 year 6 months not available

Go Full text available via Taylor \& Francis Current Content Access Available from 1997

Most recent 1 year 6 months not available

Figure 2. Highlighting and prominence. 


\section{ACCEPTED MANUSCRIPT}

Example D
Example E

\section{Serials Review}

Full Text Elsevier ScienceDirect Journals

Available from 1975

Full Text EBSCOhost Academic Search Complete

Available from 1990

Most recent 1 year 6 months not available

Full Text Taylor \& Francis Current Content Access Available from 1997

Most recent 1 year 6 months not available

Figure 3. Choice simplification. 


\section{ACCEPTED MANUSCRIPT}
Example F
Example G

\begin{tabular}{|c|c|}
\hline Serials Review & Serials Review \\
\hline Recommended & \\
\hline $\begin{array}{l}\text { Full Text Elsevier ScienceDirect Journals } \\
\text { Available from } 1975\end{array}$ & $\begin{array}{l}\text { Full Text Elsevier ScienceDirect Journals } \\
\text { Available from } 1975\end{array}$ \\
\hline $\begin{array}{l}\text { Full Text EBSCOhost Academic Search Complete } \\
\text { Available from } 1990 \\
\text { Most recent } 1 \text { year } 6 \text { months not available }\end{array}$ & $>$ See additional sources \\
\hline $\begin{array}{l}\text { Full Text Taylor \& Francis Current Content Access } \\
\text { Available from } 1997 \\
\text { Most recent } 1 \text { year } 6 \text { months not available }\end{array}$ & \\
\hline
\end{tabular}

Figure 4. Choice reduction. 